Cite this: RSC Adv., 2018, 8, 5509

Received 24th November 2017 Accepted 9th January 2018

DOI: $10.1039 / c 7 r a 12762 f$

rsc.li/rsc-advances
Check for updates

\section{A highly sensitive and selective spectrofluorimetric method for the determination of manganese at nanotrace levels in some real, environmental, biological, soil, food and pharmaceutical samples using 2-( $\alpha$-pyridyl)-thioquinaldinamide}

\begin{abstract}
M. Jamaluddin Ahmed, (DD * M. Tazul Islam and Faisal Hossain (DD
A very simple, ultra-sensitive and highly selective non-extractive spectrofluorimetric method is presented for the determination of manganese at nano-trace levels using 2-( $\alpha$-pyridyl)-thioquinaldinamide (PTQA). PTQA has been proposed as a new analytical reagent for the direct non-extractive spectrofluorimetric determination of manganese(VII). This novel fluorimetric reagent, PTQA becomes oxidized in a slightly acidic (0.0125-0.05 $\mathrm{M} \mathrm{H}_{2} \mathrm{SO}_{4}$ ) solution with manganese(vII) in absolute ethanol to produce a highly fluorescent oxidized product $\left(\lambda_{\mathrm{ex}}=319 \mathrm{~nm} ; \lambda_{\mathrm{em}}=373 \mathrm{~nm}\right.$ ). Constant and maximum fluorescence intensities were observed over a wide range of acidity $\left(0.0125-0.05 \mathrm{M} \mathrm{H}_{2} \mathrm{SO}_{4}\right)$ for the period between $5 \mathrm{~min}$ and $24 \mathrm{~h}$. Linear calibration graphs were obtained for $0.01-800 \mu \mathrm{g} \mathrm{L}^{-1}$ of $\mathrm{Mn}$, having a detection limit of $1 \mathrm{ng} \mathrm{L} \mathrm{L}^{-1}$; the quantification limit of the reaction system was found to be $10 \mathrm{ng} \mathrm{L^{-1 }}$ and the RSD was $0-2 \%$. A large excess of over 60 cations, anions and complexing agents do not interfere in the determination. The developed method was successfully used in the determination of manganese in several standard reference materials (alloys, steels, hair and sediments) as well as in some environmental waters (potable and polluted), biological samples (human blood, urine and hair), soil samples, food samples (vegetables, fruits, tea, rice, and wheat), fertilizer samples and pharmaceutical samples (multivitamin-mineral tablets and syrup), solutions containing both manganese(II) and manganese(VII) speciation and complex synthetic mixtures. The results of the proposed method for assessing biological, food and vegetables samples were comparable with AAS and ICP-MS and were found to be in excellent agreement.
\end{abstract}

\section{Introduction}

Manganese is an essential trace element in the metabolism of all living organisms, including plants and bacteria, and is found in all tissues of man. But manganese is also a potential carcinogen. ${ }^{1}$ Among the inorganic chemicals, manganese, chromium, and selenium and certain organometallic derivatives of these metals have been found to be carcinogenic under special conditions and are also considered potential inorganic genotoxic agents. ${ }^{2}$ The hazards of manganese have been known for a long time. The accurate determination of manganese in environmental and biological materials is of considerable importance for both metabolic and toxicological studies in humans and animals because of its dose-dependent harmful and beneficial roles. Until recently, analytical techniques of satisfactory sensitivity and accuracy have not been widely available and attempts by many researchers to use

Laboratory of Analytical Chemistry, Department of Chemistry, University of Chittagong, Chittagong-4331, Bangladesh. E-mail:pmjahmed55@gmail.com unsatisfactory procedures have led to the publication of much data and also to biochemical conclusions of dubious value. ${ }^{3}$ Clearly, major problems which have given rise to this situation are the very low concentrations of manganese in biological samples, and a lack of awareness of the need to exercise control over the extraneous contamination and interfering of foreign ions during all the steps of an analytical procedure. The present method that is being recommended over the existing methods almost in every respect in their own terms-selectivity, range of determination, accuracy, sensitivity, simplicity and rapidity of the operation, stability of the fluorescent system and acidity of wide variation, etc.

In expanding analytical fields such as environmental, biological and material monitoring of trace metals, there is an increasing need to develop the simple, sensitive and selective analytical techniques that do not use expensive or complicated test equipment. Many sophisticated technique, such as pulse polarography, NAA, HPLC, spectrophotometry, spectrofluorimetry, AAS, FAAS, ICP-OES and ICP-MS have been widely applied to the determination of manganese. However, the 
spectrofluorimetric method still has the advantages of being simple and without requiring expensive or complicated test equipment. For this reason, a wide variety of spectrofluorimetric methods for determination of manganese has been developed. Several authors have reported on the extractive spectrofluorimetric determination of manganese using complexes formed variety of reagents. ${ }^{4-40}$ In most of the methods ${ }^{4-40}$ cited above, manganese forms soluble or insoluble complexes with reagents with various organic solvents for spectrofluorimetric determination. Most of these reagents are expensive and non-recoverable. Most of the organic solvents which were used are carcinogenic.

The aim of this study was to develop a simpler direct spectrofluorimetric method for the nano-trace determination of manganese. In the search for a more sensitive reagent, in this work a new reagent was synthesized according to the method of Porter ${ }^{41}$ and a oxidation reaction of 2 -( $\alpha$-pyridyl)thioquinaldinamide (PTQA); with $\mathrm{Mn}(\mathrm{VII})$ and forms an intensely fluorescent oxidized product. The method possesses distinct advantages over existing methods ${ }^{\mathbf{4 - 4 0}}$ with respect to sensitivity, selectivity, range of determination, simplicity, speed, $\mathrm{pH} /$ acidity range, thermal stability, accuracy, precision and ease of operation. The method is based on the oxidative reaction of non-fluorescent PTQA in a slightly acidic (0.0125-0.05 $\mathrm{M} \mathrm{H}_{2} \mathrm{SO}_{4}$ ) solution with $\mathrm{Mn}$ (VII) in presence of ethanol to produce a highly fluorescent oxidized product, followed by a direct measurement of the fluorescence intensity in an aqueous solution at room temperature. Oxidation is very rapid and no extraction is required. With suitable masking, the reaction can be made to be highly selective and the reagent blank solutions do not show any fluorescence.

\section{Experimental section}

\section{Apparatus}

A Shimadzu (Kyoto, Japan) (Model-RF-5301PC) Spectrofluorophotometer and a Jenway (England, UK) (Model-3010) pH meter with combination of electrodes were used for measurements of the fluorescence intensity and $\mathrm{pH}$, respectively. The calibration and linearity of the instrument were frequently checked with standard quinine sulphate $\left(10 \mu \mathrm{g} \mathrm{L}^{-1}\right)$. A Thermo Fisher Scientific (Model-iCE 3000, origin USA) atomic absorption spectrophotometer equipped with a microcomputercontrolled nitrous oxide-acetylene flame and an Inductively Coupled Plasma-Mass Spectrometer (ICP-MS), Model - ELAN DRC-II, Perkin Elmer (Toronto, Canada) were used to compare of the results. The Elemental Analyzer (Exeter Analytical Inc. Model: CE 440) equipped with supersensitive thermal conductivity detector for simultaneous determination of $\mathrm{CHN}$ was used. Infrared spectrum was recorded with FTIR Spectrophotometer, Shimadzu (Model-IR Prestige 21, Detector-DTGS KBr) in the range $7500-350 \mathrm{~cm}^{-1}$ and model: JEOL 500SS, magnetic field strength: $500 \mathrm{MHz}$, solvent used: DMSO D6, standard: TMS, four channel NMR spectrometer with signal-to-noise ratio of $\sim 5000: 1$ for proton were used for characterization of the ligand.

\section{Synthesis and characterization of the reagent}

Synthesis of the reagent (PTQA). 2-( $\alpha$-Pyridyl) thioquinaldinamide (PTQA, $\mathrm{C}_{15} \mathrm{H}_{11} \mathrm{~N}_{3} \mathrm{~S}$ ). (molecular wt. = 265.18) was synthesized according to the method of Porter. ${ }^{41}$ The mixture containing 2-aminopyridin, quinaldine and sulphur powder in the molar ratio of $2: 1: 1.5$ were mixed and refluxed for 6 hours in $250 \mathrm{~mL}$ round bottom flask fitted with bulb condenser under controlled temperature (140-150) ${ }^{\circ} \mathrm{C}$ at 1 atm. Pressure over oil bath. The reaction mixture was kept overnight. The thiocompound was filtered and crystallized using petroleum ether $(60-80)^{\circ} \mathrm{C}$ to give a bright yellow crystalline (needle shaped) solid. The compound recrystallized from lime-distilled ethanol and was kept under vacuum $(0.1 \mathrm{~mm}$ of $\mathrm{Hg})$ for 24 hours. Yield of the product was $70 \%$. The structure of the reagent is shown in Scheme 1.

Characterization of the reagent. The reagent (PTQA) was characterized by taking the melting point, elemental analysis and an FTIR spectrum and ${ }^{1}$ HNMR spectrum and thermogravimetric analysis. The melting point of the synthesized compound (PTQA) was $155 \pm 2{ }^{\circ} \mathrm{C}$ (lit. $155 \pm 1{ }^{\circ} \mathrm{C}$ ) ${ }^{41}$ which indicated the purity of PTQA.

The results elemental analysis $(\mathrm{C}=72.25, \mathrm{~N}=13.35$ and $\mathrm{H}=$ $4.25 \%$ ) of the reagent are very in good agreement with the calculated values $(\mathrm{C}=72.43, \mathrm{~N}=13.55$ and $\mathrm{H}=4.55 \%)$. The FTIR spectrum of prepared reagent (PTQA) is shown in Fig. 1. The presence of FTIR peak at $1126.43 \mathrm{~cm}^{-1}$ in Fig. 1 was due to the characteristic $\mathrm{C}=\mathrm{S}$ double bond peak $\left(v^{\mathrm{C}=\mathrm{S}}, 1050-\right.$ $\left.1200 \mathrm{~cm}^{-1}\right)^{41}$ of the reagent indicating the formation of PTQA. Both FTIR spectral and elemental analysis data indicated the formation of the reagent PTQA. The formation of the reagent also tested by ${ }^{1}$ HNMR spectrum is shown in Fig. 2. The steadiness of the thermogravimetric curve obtained for about $1 \mathrm{~g}$ of the reagent at $80-90^{\circ} \mathrm{C}$ indicated that the reagent did not contain any moisture.

The elemental analysis were performed by the National Center of Excellence in Analytical Chemistry, University of Sindh, Pakistan and FTIR spectra was recorded with FTIR

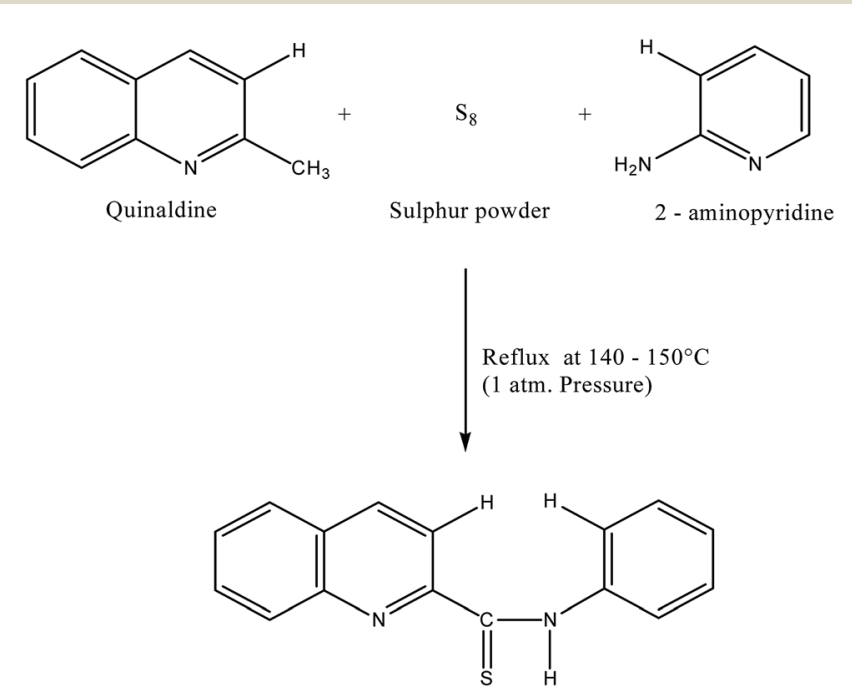

Scheme 1 Reaction scheme of 2-( $\alpha$-pyridyl)-thioquinaldinamide (PTQA). 


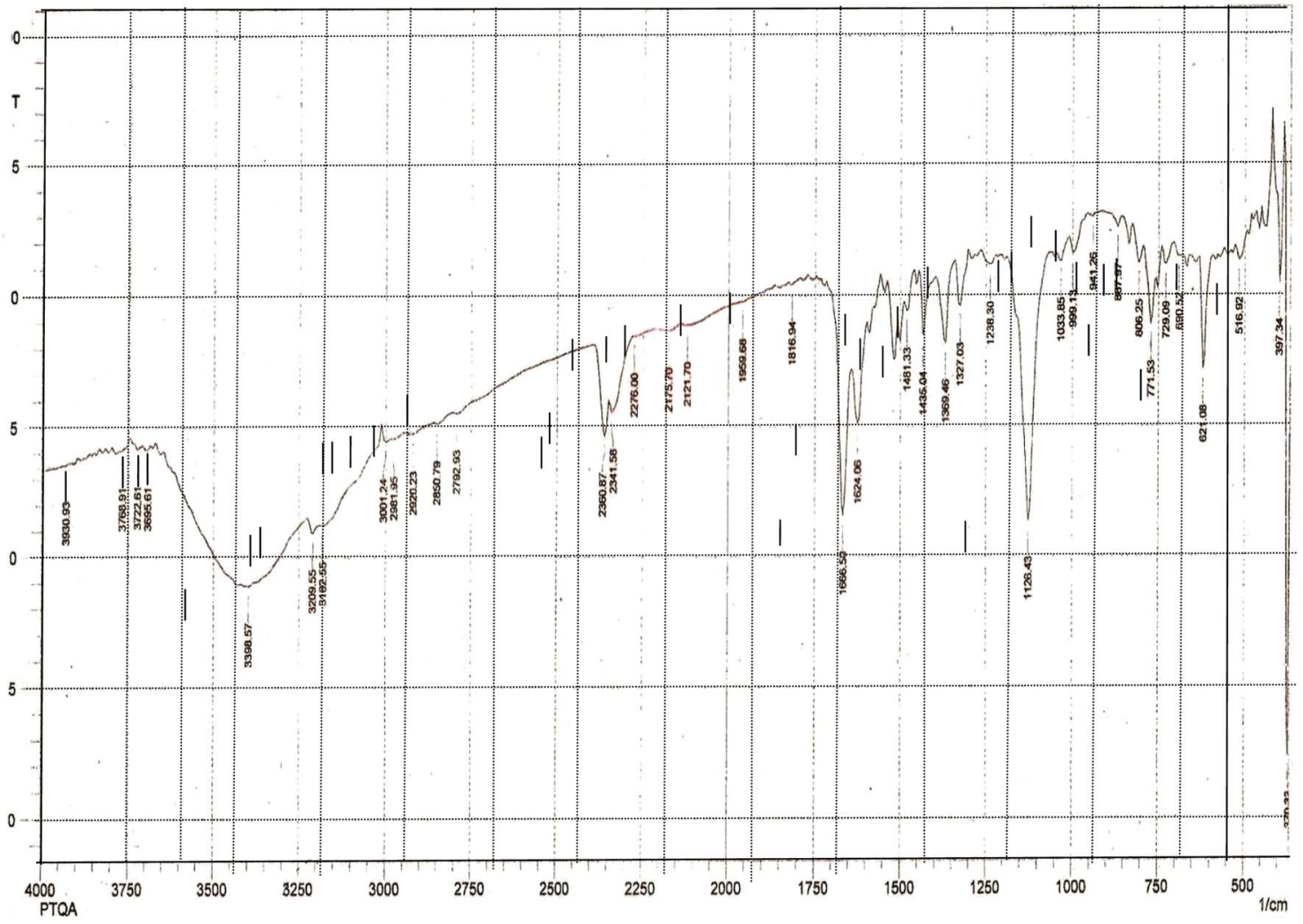

Fig. 1 FTIR spectrum of 2-( $\alpha$-pyridyl) thioquinaldinamide.

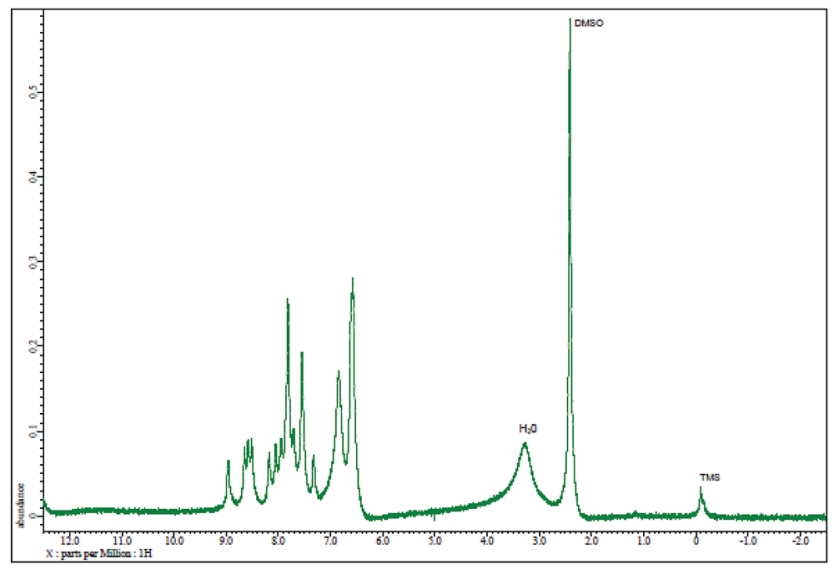

Fig. $2{ }^{1}$ HNMR spectrum of 2 -( $\alpha$-pyridyl)-thioquinaldinamide.

spectrophotometer, Shimadzu (Model-IR Prestige 21, DetectorDTGS KBR) in the range $7500-350 \mathrm{~cm}^{-1}$ from our laboratory and ${ }^{1} \mathrm{HNMR}$ spectrum was recorded with ${ }^{1} \mathrm{HNMR}$ spectrophotometer model: JEOL 500SS from Kanazawa University, Japan.

Live subject statement. We were not aiming to carry out detailed human studies but some samples from individuals were used in our study and as such we abided by all the necessary procedures and regulations and our University gave consent. University of Chittagong, Bangladesh is committed to the protection and safety of human subjects involved in research.

\section{Reagents and solutions}

All the chemicals used were of analytical reagent grade of the highest purity available. High-purity absolute ethanol and highpurity de-ionized water were used throughout. High-purity water was obtained by passing tap water through cellulose absorbent and to mixed-bed ion exchange columns, followed by distillation in a corning AG-11 unit. Glass vessel were cleaned by soaking in acidified solutions of $\mathrm{KMnO}_{4}$ or $\mathrm{K}_{2} \mathrm{Cr}_{2} \mathrm{O}_{7}$ followed by washing with concentrated $\mathrm{HNO}_{3}$ and rinsed several times with high purity de-ionized water. Stock solutions and environmental water sample (1000 mL each) were kept in polypropylene bottles containing $1 \mathrm{~mL}$ concentrated $\mathrm{HNO}_{3}$. More rigorous contamination control was used when the manganese levels in the specimens were low.

\section{PTQA solution $\left(1 \times 10^{-3} \mathrm{M}\right)$}

The reagent solution was prepared by dissolving the requisite amount $(0.0024 \mathrm{~g})$ of PTQA, in a known volume $(10 \mathrm{~mL})$ of absolute ethanol. A freshly prepared reagent solution $\left(10^{-4} \mathrm{M}\right)$ was used whenever required.

\section{Manganese(VII) standard solution $\left(1.82 \times 10^{-2} \mathrm{M}\right)$}

A $100 \mathrm{~mL}$ amount of stock solution $\left(1 \mathrm{mg} \mathrm{mL}^{-1}\right)$ of heptavalent manganese was prepared by dissolving $287.66 \mathrm{mg}$ of potassium permanganate $\left(\mathrm{KMnO}_{4}\right)$ (Aldrich A.C.S. grade) in doubly distilled de-ionized water. Aliquots of this solution were 
standardized with oxalic acid. ${ }^{\mathbf{4 2}}$ More dilute standard solutions were prepared by appropriate dilution of aliquots from the stock solution with de-ionized water when required. A freshly standardized solution was always used.

\section{Mn(II) standard solution $\left(1.82 \times 10^{-2} \mathrm{M}\right)$}

A $100 \mathrm{~mL}$ amount of stock solution $\left(1 \mathrm{mg} \mathrm{\textrm {L } ^ { - 1 }}\right)$ of divalent manganese was prepared by dissolving $307.7 \mathrm{mg}$ of purifiedgrade (E Merck proanalysis grade) monohydrated manganese sulphate $\left(\mathrm{MnSO}_{4} \cdot \mathrm{H}_{2} \mathrm{O}\right)$ (super special grade J. T. Baker) in doubly distilled de-ionized water. Aliquots of this solution were standardized titrimetrically with disodiumdihydrogenethylenediaminetetraacetate $\left(\mathrm{Na}_{2} \mathrm{H}_{2}\right.$ EDTA) using Eriochrome Black T. ${ }^{42}$ More dilute standard solutions were prepared by appropriate dilution of aliquots from the stock solution with de-ionized water as and when required.

\section{Potassium dichromate solution}

A $100 \mathrm{~mL}$ amount of stock solution $(0.1 \mathrm{~N})$ was prepared by dissolving $500 \mathrm{mg}$ of finely powdered $\mathrm{K}_{2} \mathrm{Cr}_{2} \mathrm{O}_{7}$ (Merck) in $100 \mathrm{~mL}$ de-ionized water.

\section{Ammonium persuphate solution}

Ammonium persuphate solution (2\% w/v) (A.C.S.-grade 99\% pure) was freshly prepared by dissolving $2 \mathrm{~g}$ in $100 \mathrm{~mL}$ of deionized water.

\section{Tartrate solution}

A $100 \mathrm{~mL}$ stock solution of tartrate $(0.01 \% \mathrm{w} / \mathrm{v})$ was prepared by dissolving $10 \mathrm{mg}$ of A.C.S.-grade (99\%) potassium sodium tartrate tetrahydrate in $(100 \mathrm{~mL})$ de-ionized water.

\section{Aqueous ammonia solution}

A $100 \mathrm{~mL}$ solution of an aqueous ammonia solution was prepared by diluting $10 \mathrm{~mL}$ concentrated $\mathrm{NH}_{4} \mathrm{OH}(28-30 \%$, A.C.S.-grade) to $100 \mathrm{~mL}$ with de-ionized water. The solution was stored in a polypropylene bottle.

\section{EDTA solution}

A $100 \mathrm{~mL}$ stock solution of EDTA $(0.01 \% \mathrm{w} / \mathrm{v})$ was prepared by dissolving $10 \mathrm{mg}$ A.C.S.-grade ( $\geq 99 \%$ ) ethylenediaminetetraacetic acid as disodium salt dihydrate in $(100 \mathrm{~mL})$ de-ionized water.

\section{Other solutions}

Solutions of a large number of inorganic ions and complexing agents were prepared from their AnalaR grade or equivalent grade water-soluble salts (or the oxides and carbonates in hydrochloric acid); those of niobium, tantalum, titanium, zirconium and hafnium were specially prepared from their corresponding oxides (Specpure, Johnson Matthey) according to the recommended procedures of Mukharjee. ${ }^{43}$ In the case of insoluble substances, special dissolution methods were adopted. $^{\mathbf{4 4}}$

\section{Procedure}

To $0.1-1.0 \mathrm{~mL}$ of a neutral aqueous solution containing 0.1$8000 \mathrm{ng}$ of manganese(vII) in a $10 \mathrm{~mL}$ calibrated flask was mixed with a 1 : 70-1 : 300 fold molar excess (preferably $1 \mathrm{~mL}$ of $1 \times 10^{-4} \mathrm{M}$ ) of the 2-( $\alpha$-pyridyl) thioquinaldinamide (PTQA) reagent solution followed by the addition of $0.5-2 \mathrm{~mL}$ (preferably $1 \mathrm{~mL}$ ) of $0.025 \mathrm{M}$ of sulfuric acid. The solution was mixed well and allowed to stand for 5 min after which $2 \mathrm{~mL}$ of absolute ethanol was added and the mixture was diluted to the mark with de-ionized water. The fluorescence intensity of the system was measured at $373 \mathrm{~nm}$ against a corresponding reagent blank, prepared concurrently, keeping the excitation wavelength maximum at $319 \mathrm{~nm}$ and the instrument setting the same. The manganese content in an unknown sample was determined using a concurrently prepared calibration graph.

\section{Sample collection and preservation}

Environmental samples. Water and soil samples were collected in polythene bottles from different places of Bangladesh. After collection, $\mathrm{HNO}_{3}\left(1 \mathrm{~mL} \mathrm{~L}^{-1}\right)$ was added as preservative.

Blood and urine. Blood and urine samples were collected in polythene bottles from effected persons of Chittagong Medical College Hospital, Bangladesh. Immediately after collection they were stored in a salt-ice mixture and latter, at the laboratory, were at $-20{ }^{\circ} \mathrm{C}$.

Soil samples. Soil samples were collected from different locations of Bangladesh. Samples were dried in air and homogenized with a mortar.

Food samples. Food samples (rice, wheat, tea, fruits and vegetables) were collected from local market of Chittagong. After collection the samples (fruits and vegetables) were stored in refrigerator for preservation. Samples (rice, wheat, tea) were used as dry condition and homogenized with a mortar.

Pharmaceutical samples. Pharmaceutical samples (tablet and syrup) of different companies were collected from local pharmacy of Chittagong. Samples (tablet) were homogenized with a mortar.

Fertilizer samples. Fertilizer samples of different verities were collected from local market of Chittagong. Samples were homogenized with a mortar.

\section{Results and discussion}

\section{Factors affecting the fluorescence intensity}

Spectral characteristics. The excitation and emission spectra of the fluorescent $\mathrm{Mn}$ (VII)-PTQA in $0.025 \mathrm{M}$ sulfuric acid medium was recorded using the spectrofluorophotometer. The excitation and emission maxima were at $319 \mathrm{~nm}$ and $373 \mathrm{~nm}$, respectively. The reagent blank exhibited negligible fluorescence, despite having wavelength maximum in the same region. In all instances, measurements were made against the reagent blank. The spectra are shown in Fig. 3. 


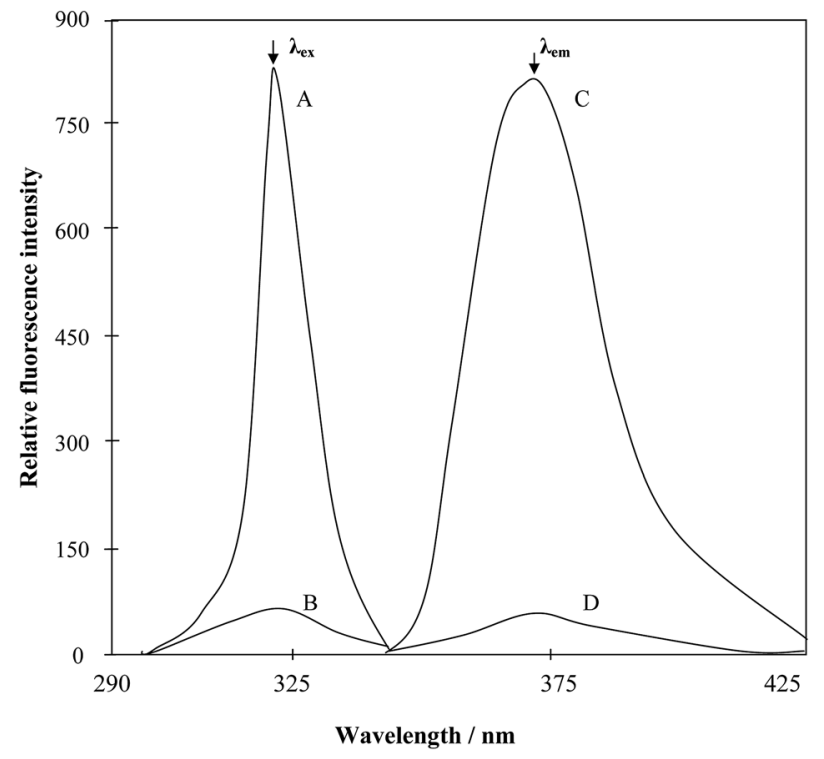

Fig. 3 (A and B), Excitation spectra of the $M n^{\mathrm{VII}}-\mathrm{PTQA}$ system and the reagent blank $\left(\lambda_{\mathrm{em}}=373 \mathrm{~nm}\right)$; and $(C$ and $D)$ are the corresponding emission spectra $\left(\lambda_{\mathrm{ex}}=319 \mathrm{~nm}\right)$.

\section{Optimization of some parameters on the fluorescence intensity}

Effect of solvent. Because PTQA is insoluble in water, an organic solvent was used for the system. Of the various solvents [chloroform, benzene, carbon tetrachloride, $n$ butanol, isobutanol, ethanol, 1,4-dioxane and $\mathrm{N}, \mathrm{N}$-dimethylformamide (DMF)] were tested for the system, ethanol was found to be the best solvent for the system. The effect of ethanol on the fluorescence intensity was studied and no adverse effect was observed over a wide range of ethanol concentrations. It was observed that Mn(vII)-PTQA system with $10 \mu \mathrm{g} \mathrm{L}^{-1}$ of $\mathrm{Mn}$ in absolute ethanol solution produced a constant fluorescence intensity as shown in Fig. 4. A concentration of $20 \% \mathrm{v} / \mathrm{v}$ ethanol in the final volume was sufficient to prevent any precipitation or turbidity and to allow

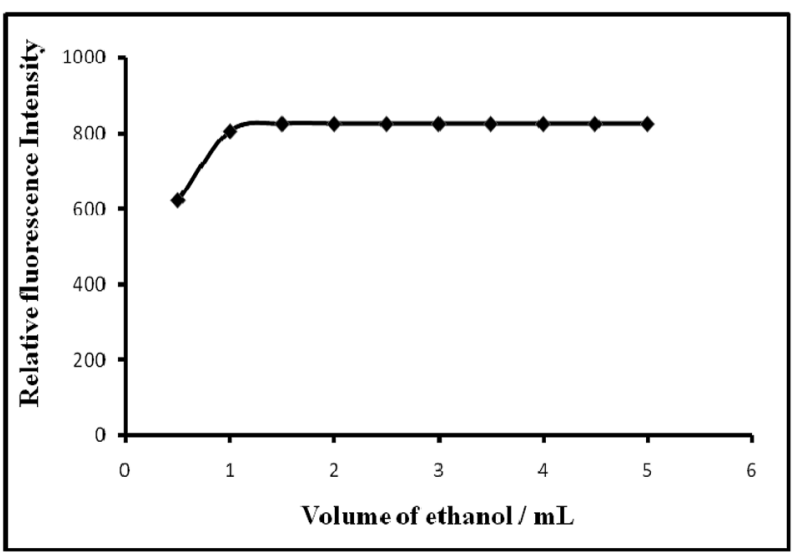

Fig. 4 Effect of solvent (ethanol) on the fluorescence of Mn(VII)-PTQA system. accurate measurements. Therefore, a $20 \% \mathrm{v} / \mathrm{v}$ ethanolic solution was used in the recommended procedure.

Effect of acidity. Of the various acids (nitric, sulfuric, hydrochloric and phosphoric) studied, sulfuric acid was found to be the best acid for the system. Although $\mathrm{H}_{3} \mathrm{PO}_{4}$ was used previously to be most suitable $\operatorname{acid}^{45}$ for the oxidation of manganese(II) but the proposed procedure for the spectrofluorimetric determination of manganese(vII) with PTQA $\mathrm{H}_{2} \mathrm{SO}_{4}$ is more better than $\mathrm{H}_{3} \mathrm{PO}_{4}$. The fluorescence intensity was at maximum and constant when the $10 \mathrm{~mL}$ of solution $\left(10 \mu \mathrm{g} \mathrm{L}^{-1}\right.$ of (VII)) contained $0.5-2.0 \mathrm{~mL}$ of $0.025 \mathrm{M}$ sulfuric acid at room temperature $\left(25 \pm 5{ }^{\circ} \mathrm{C}\right)$. Outside this range of acidity, the fluorescence intensity decreased (Fig. 5). The optimum acidity range in the final solution is therefore 0.0125-0.05 $\mathrm{M} \mathrm{H}_{2} \mathrm{SO}_{4}$. For all subsequent measurements $1 \mathrm{~mL}$ of $0.025 \mathrm{M}$ sulfuric acid was added.

Effect of temperature. The Mn(VII)-PTQA system attained maximum and constant fluorescence intensity at (15-40) ${ }^{\circ} \mathrm{C}$ temperature. For all subsequent measurements was done at room temperature $\left(25 \pm 5^{\circ} \mathrm{C}\right)$.

Effect of time. The reaction is instantaneous. The $\mathrm{Mn}(\mathrm{VII})-$ PTQA system attained maximum and constant fluorescence intensity immediately (within $5 \mathrm{~min}$ ) after dilution of the solution to the final volume, which then remained strictly unaltered for $24 \mathrm{~h}$ at room temperature $\left(25 \pm 5{ }^{\circ} \mathrm{C}\right)$.

Effect of reagent concentration. Different molar excesses of PTQA were added to a fixed metal ion concentration and fluorescence intensities were measured according to the standard

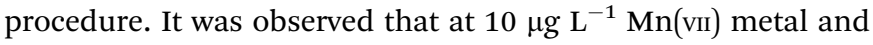
the reagent molar ratios of $1: 70-1: 300$ produced a constant fluorescence intensity of the oxidized product. Outside this range of reagent, the fluorescence intensity decreased (Fig. 6). At different manganese(vII) concentrations ( 0.5 and $\left.1 \mu \mathrm{g} \mathrm{L}^{-1}\right)$, the effect of varying the reagent concentration was similar. For all subsequent measurements $1 \mathrm{~mL}$ of $1 \times 10^{-4} \mathrm{M}$ PTQA reagent was added.

Effect of metal concentration. The well-known equation for spectrofluorimetric analysis in very dilute solutions derived from Beer's law. The effect of metal concentration was studied over $0.001-1000 \mu \mathrm{g} \mathrm{L}^{-1}$ distributed in six different sets (0.001$0.01,0.01-0.1,0.1-1,1-10,10-100$ and $100-1000 \mu \mathrm{g} \mathrm{L} \mathrm{L}^{-1}$ ) for

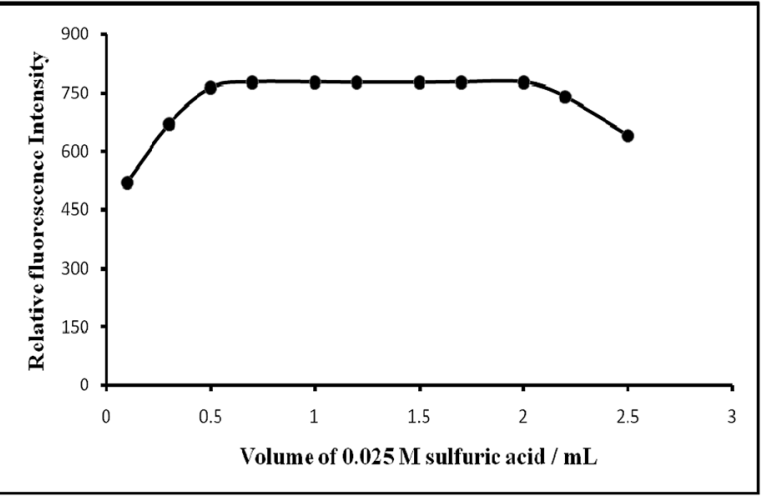

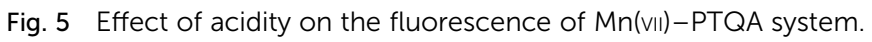




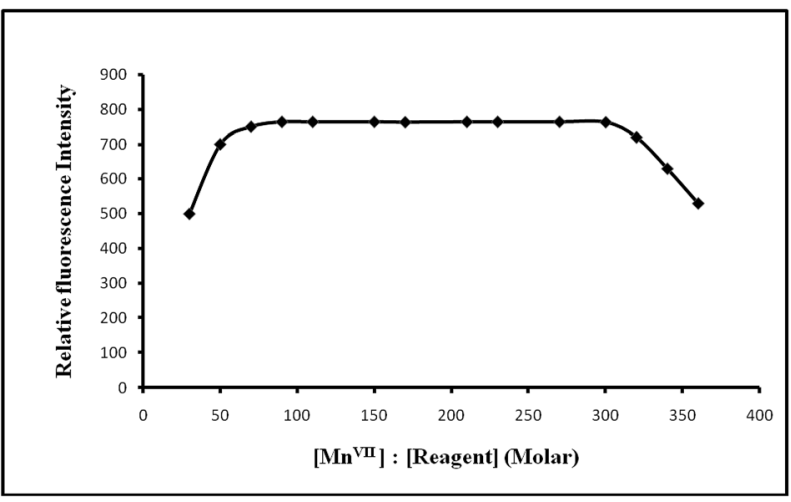

Fig. 6 Effect of reagent on the fluorescence of $M n(V I I)-P T Q A$ system.

Fig. 6 . Effect of reagent on the fluorescence of Mn( $\mathrm{nI}$ )-PTQA system.

convenience of measurement. The fluorescence intensity was linear over a wide range $\left[10 \mathrm{pg} \mathrm{mL}^{-1}\right.$ to $800 \mathrm{ng} \mathrm{mL}^{-1}$ for $0.01-$ $800 \mu \mathrm{g} \mathrm{L}^{-1}$ ] of manganese at excitation wavelength at $319 \mathrm{~nm}$ and emission wavelength at $373 \mathrm{~nm}$ representing five linear graphs (0.01-0.1, 0.1-1.0, 1-10, 10-100 and 100-1000 $\left.\mathrm{gg} \mathrm{L}^{-1}\right)$. Of five calibration graphs, the one showing the limit of the linearity range (Fig. 7); the next four were straight-line graphs passing through the origin $\left(R^{2}=0.9998\right)$. The limit of detection and limit of quantization were found to be $1 \mathrm{pg} \mathrm{mL}^{-1}$ and $10 \mathrm{pg} \mathrm{mL}^{-1}$, respectively. The selected analytical parameters obtained with the optimization experiments are summarized in Table 1.

Effect of foreign ions. More than 60 anions, cations and complexing agents were studied individually to investigate their effect on the determination of $10 \mu \mathrm{g} \mathrm{L}^{-1}$ of manganese(viI). The criterion for an interference ${ }^{45}$ was a fluorescence intensity value varying by more than $\pm 5 \%$ from the expected value for manganese alone. The results are summarized in Table 2 . As can be seen a large number of ions have no significant effect on the determination of manganese. The most serious interference were from $\operatorname{Se}(\mathrm{rv}), \operatorname{Cr}(\mathrm{vI})$ and

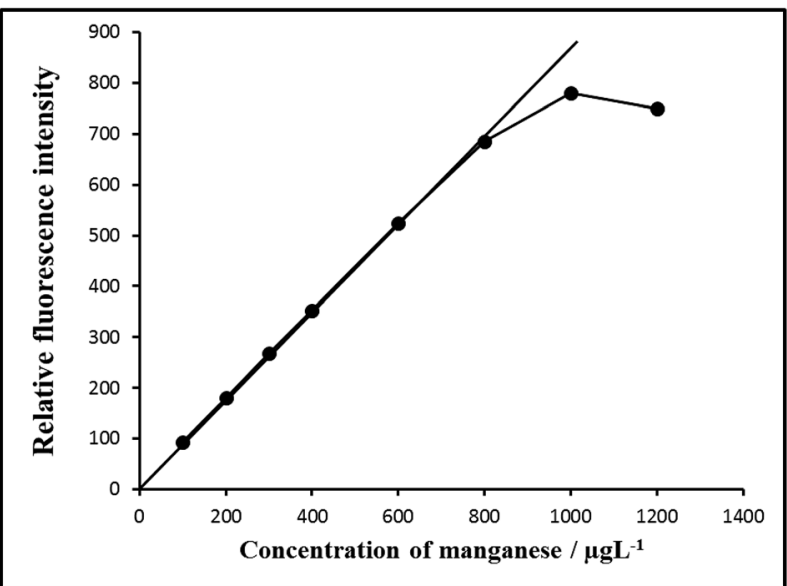

Fig. 7 Calibration graph E: $100-800 \mu \mathrm{g} \mathrm{L}^{-1}$ of manganese(VII). Bandwidth: Ex. slit-1.5, Em. slit-1.5, sensitivity: high.
Table 1 Selected analytical parameters obtained with the optimization experiments

\begin{tabular}{|c|c|c|}
\hline Parameters & Studied range & Selected value \\
\hline $\begin{array}{l}\text { Excitation wavelength } \\
\text { maximum } / \lambda_{\text {ex }}(\mathrm{nm})\end{array}$ & $200-700$ & 319 \\
\hline $\begin{array}{l}\text { Emission wavelength } \\
\text { maximum } / \lambda_{\mathrm{em}}(\mathrm{nm})\end{array}$ & $200-700$ & 373 \\
\hline $\begin{array}{l}\text { Solvent/amount of } \\
\text { absolute ethanol/mL }\end{array}$ & $0-6$ & 1-5 (preferably 2) \\
\hline Acidity $/ \mathrm{M} \mathrm{H}_{2} \mathrm{SO}_{4}$ & $0.001-0.075$ & $\begin{array}{l}0.0125-0.05 \\
\text { (preferably } 0.025 \text { ) }\end{array}$ \\
\hline $\mathrm{pH}$ & $3.69-0.69$ & $\begin{array}{l}3.0-1.0 \\
\text { (preferably } 1.3 \text { ) }\end{array}$ \\
\hline Time/h & $0-72$ & $\begin{array}{l}1 \mathrm{~min}-24 \mathrm{~h} \\
(\text { preferably } 5 \mathrm{~min})\end{array}$ \\
\hline Temperature $/{ }^{\circ} \mathrm{C}$ & $10-70$ & $\begin{array}{l}15-40 \\
\text { (preferably } 25 \pm 5 \text { ) }\end{array}$ \\
\hline $\begin{array}{l}\text { Reagent } \\
\text { (fold molar excess, } \mathrm{M}: \mathrm{R} \text { ) }\end{array}$ & $1: 1-1: 500$ & $\begin{array}{l}1: 70-1: 300 \\
\text { (preferably } 1: 100 \text { ) }\end{array}$ \\
\hline Linear range $/ \mu \mathrm{g} \mathrm{L}^{-1}$ & $0.001-1000$ & $0.01-800$ \\
\hline Limit of quantification/ng $\mathrm{L}^{-1}$ & $1-100$ & 10 \\
\hline Detection limit/ng $\mathrm{L}^{-1}$ & $0.01-10$ & 1 \\
\hline Reproducibility (\% RSD) & $0-10$ & $0-2 \%$ \\
\hline Regression co-efficient $\left(R^{2}\right)$ & $0.9992-0.9999$ & 0.9998 \\
\hline
\end{tabular}

Table 2 Table of tolerance limits of foreign ions ${ }^{a}$, tolerance ratio $\left[\operatorname{species}(\mathrm{x}) / M_{\mathrm{n}}(\mathrm{w} / \mathrm{w})\right]$

\begin{tabular}{|c|c|c|c|}
\hline Species $\mathrm{x}$ & $\begin{array}{l}\text { Tolerance } \\
\text { ratio } \mathrm{x} / M_{\mathrm{n}}(\mathrm{w} / \mathrm{w})\end{array}$ & Species x & $\begin{array}{l}\text { Tolerance } \\
\text { ratio } \mathrm{x} / M_{\mathrm{n}}(\mathrm{w} / \mathrm{w})\end{array}$ \\
\hline Ammonium(I) & 1000 & Lithium & 1000 \\
\hline Arsenic(III) & $500^{b}$ & Lead(II) & 200 \\
\hline Arsenic(v) & 500 & Magnesium & 1000 \\
\hline Aluminum & 200 & $\begin{array}{l}\text { Manganese(II), } \\
\text { manganese(IV) }\end{array}$ & 1000,500 \\
\hline Azide & 200 & Mercury(II) & 200 \\
\hline Ascorbic acid & 1000 & Molybdenum(vi) & 500 \\
\hline Antimony & 500 & Nitrate & 1000 \\
\hline Bromide & 100 & Nickel & 500 \\
\hline Bismuth(III) & 500 & Oxalate & 1000 \\
\hline Beryllium(II) & 1000 & Potassium & 1000 \\
\hline Calcium & 1000 & Phosphate & 1000 \\
\hline Chloride & 1000 & Selenium(vi) & 500 \\
\hline Cobalt(II) & $200^{c}$ & Selenium(Iv) & $50^{c}$ \\
\hline Cobalt(III) & 500 & Silver & 500 \\
\hline Chromium(III) & 1000 & Sodium & 1000 \\
\hline Chromium(vI) & $100^{c}$ & Strontium & 500 \\
\hline Cadmium & 1000 & Sulfate & 500 \\
\hline Carbonate & 1000 & Titanium(Iv) & 100 \\
\hline Cesium & 1000 & Tellurium(Iv) & 500 \\
\hline Citrate & 1000 & Tartrate & 1000 \\
\hline Cerium(III) & 500 & Copper(II) & 500 \\
\hline Cerium(Iv) & $500^{b}$ & Thiocyanate & 1000 \\
\hline Cyanide & 200 & Thiourea & 100 \\
\hline EDTA & 1000 & Tungsten(vi) & 1000 \\
\hline Fluoride & 1000 & $\operatorname{Tin}(\mathrm{II})$ & $50^{b}$ \\
\hline Iodide & 1000 & $\operatorname{Tin}(\mathrm{Iv})$ & $50^{b}$ \\
\hline Iron(II) & 200 & Vanadium(v) & 1000 \\
\hline Iron(III) & 200 & Zinc & 1000 \\
\hline
\end{tabular}

${ }^{a}$ Tolerance limit was defined as ratio that causes less than \pm 5 percent interference. ${ }^{b}$ With $10 \mathrm{mg} \mathrm{L}^{-1}$ tartrate. ${ }^{c}$ With $10 \mathrm{mg} \mathrm{L}^{-1}$ EDTA. 
Table 3 Determination of manganese in certified reference materials

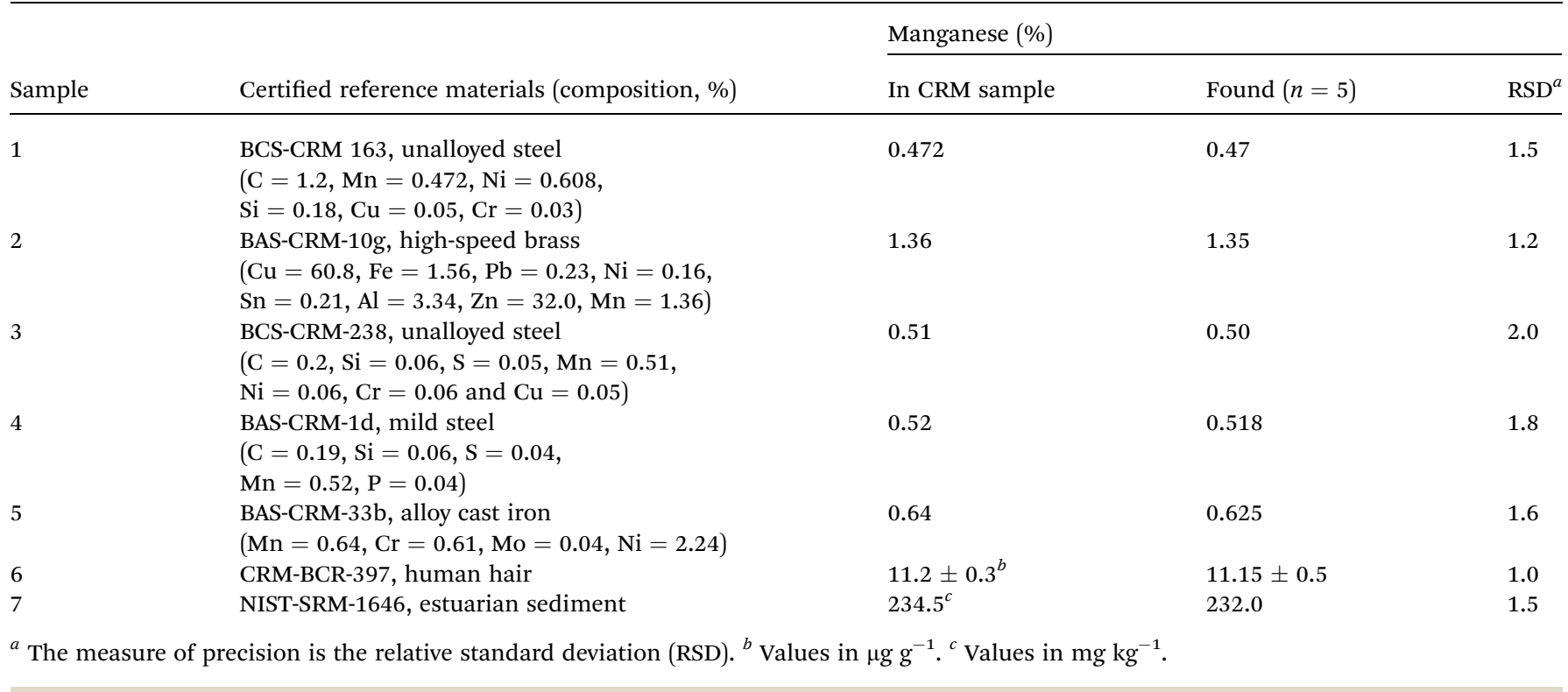

$\mathrm{Ce}(\mathrm{Iv})$ ions. Interference from these ions is probably due to oxidative product formation with PTQA.

The greater tolerance limits for these ions can be achieved by using several masking agents. In order to eliminate the interference of $\mathrm{Se}(\mathrm{Iv}), \mathrm{Cr}(\mathrm{VI})$ and $\mathrm{Ce}(\mathrm{Iv})$ ions, EDTA and tartrate can be used as masking agents, respectively. ${ }^{46} \mathrm{~A}$ 50, 100 and 500 -fold excess of $\mathrm{Se}(\mathrm{Iv}), \mathrm{Cr}(\mathrm{VI})$ and $\mathrm{Ce}(\mathrm{Iv})$ ions could be masked with EDTA and tartrate, respectively. During the interference studies, if a precipitate was formed, it was removed by centrifugation. The amount mentioned is not the tolerance limit but the actual amount studied. However, for those ions whose tolerance limits have been studied, their tolerance ratios are mentioned in Table 2 .
Strong reducing agents such as tin(II), chloride, iron(II), sulphate, hydroxylamine, hydrochloride and sodium azide, which would otherwise reduce manganese(viI), undergo oxidation during the treatment of manganese(II) solution with persulphate and hence are not a problem.

Precision and accuracy. The precision of the present method was evaluated by determining different concentrations of manganese (each analyzed at least five times). The relative standard deviation $(n=5)$ was $2-0 \%$ for $0.1-8000 \mathrm{ng}$ of manganese(VII) in $10 \mathrm{~mL}$, indicating that this method is highly precise and reproducible (Table 1 ). The detection limit (3 s of the blank) and limit of quantization (10 times of detection limit)

Table 4 Determination of manganese in some environmental water samples

\begin{tabular}{|c|c|c|c|c|c|}
\hline \multirow[b]{2}{*}{ Sample } & & \multicolumn{2}{|c|}{ Manganese $/ \mu \mathrm{g} \mathrm{L} \mathrm{L}^{-1}$} & \multirow[b]{2}{*}{ Recovery $\pm s(\%)$} & \multirow[b]{2}{*}{$s_{\mathrm{r}}^{b}(\%)$} \\
\hline & & Added & Found $^{a}(n=5)$ & & \\
\hline Well water & & $0,10,50$ & $35.0,45.0,85.0$ & $100 \pm 0.0,100 \pm 0.0$ & $0.00,0.00$ \\
\hline \multirow[t]{2}{*}{ River water } & Karnaphully (upper) & $0,10,50$ & $75.0,88.0,125.0$ & $104.0 \pm 06,100.0 \pm 0.0$ & $0.35,0.00$ \\
\hline & Karnaphully (lower) & $0,10,50$ & $80.5,90.0,135.0$ & $99.5 \pm 0.5,103.0 \pm 0.8$ & $0.21,0.39$ \\
\hline \multirow[t]{2}{*}{ Sea water } & Bay of Bengal (upper) & $0,10,50$ & $25.0,35.0,80.0$ & $100.0 \pm 0.0,106.0 \pm 1.0$ & $0.00,0.45$ \\
\hline & Bay of Bengal (lower) & $0,10,50$ & $35.0,45.0,90.0$ & $100.0 \pm 0.0,105.8 \pm 1.0$ & $0.00,0.38$ \\
\hline \multirow[t]{4}{*}{ Drain water } & T. S. P. Complex ${ }^{c}$ & $0,100,500$ & $130.0,235.0,630.0$ & $102.0 \pm 0.8,100.2 \pm 0.0$ & $0.18,0.00$ \\
\hline & $\mathrm{PHP}^{d}$ & $0,100,500$ & $160.0,260.0,665.0$ & $100.0 \pm 0.0,100.7 \pm 0.5$ & $0.00,0.25$ \\
\hline & $\mathrm{BSRM}^{e}$ & $0,100,500$ & $245.0,350.0,750.0$ & $101.0 \pm 0.8,100.6 \pm 1.0$ & $0.29,0.35$ \\
\hline & K. P. M. water ${ }^{f}$ & $0,100,500$ & $188.0,288.0,690.0$ & $100.0 \pm 0.8,100.2 \pm 0.5$ & $0.00,0.42$ \\
\hline
\end{tabular}

${ }^{a}$ Average of five replicate determinations of each sample. ${ }^{b}$ The measure precision is the relative standard deviation $\left(s_{\mathrm{r}}\right) .{ }^{c} \mathrm{~T} . \mathrm{S} . \mathrm{P} . \mathrm{Complex}$ Ltd., Patenga, Chittagong. ${ }^{d}$ PHP Glass factory, Chittagong. ${ }^{e}$ Bangladesh Steel Re-rolling Mills Ltd. (BSRM), Baizid Bosthami, Chittagong.

${ }^{f}$ Karnaphuly Paper Mills, Chandraghona, Chittagong. ${ }^{g}$ Berger Paints Bangladesh Limited, Kalurghat, Chittagong. 
Table 5 Determination results of manganese for human fluids and hair

\begin{tabular}{|c|c|c|c|c|}
\hline \multirow[b]{2}{*}{ Serial no. } & \multirow[b]{2}{*}{ Sample } & \multicolumn{2}{|l|}{ Manganese $/ \mu \mathrm{g} \mathrm{L^{-1 }}$} & \multirow[b]{2}{*}{ Sample source $^{a}$} \\
\hline & & AAS $(n=5)$ & Proposed method $(n=5)$ & \\
\hline 4 & Blood, urine & $370.6 \pm 1.5,93.5 \pm 1.8$ & $372.5 \pm 1.8,98.5 \pm 2.2$ & $\begin{array}{l}\text { Pneumonitis (manganic } \\
\text { pneumonia) patient (male) }\end{array}$ \\
\hline 5 & Blood, urine & $230.8 \pm 1.6,85.6 \pm 2.0$ & $232.5 \pm 2.0,85.6 \pm 1.8$ & Hypertension patient (male) \\
\hline 6 & Blood, urine & $110.0 \pm 2.1,30.5 \pm 1.9$ & $115.0 \pm 2.0,32.8 \pm 2.5$ & Asthma patient (male) \\
\hline 7 & Blood, urine & $15.5 \pm 2.0,3.85 \pm 1.5$ & $15.8 \pm 1.5,3.82 \pm 1.8$ & Normal adult (male) \\
\hline 8 & Hair $^{b}$ & $790.5 \pm 1.8$ & $795.8 \pm 1.5$ & Normal human hair (male) \\
\hline
\end{tabular}

for manganese(viI) were found to be $1 \mathrm{ng} \mathrm{L}^{-1}$ and $10 \mathrm{ng} \mathrm{L}^{-1}$, respectively. The method was also tested by analyzing several synthetic mixtures containing manganese(vII) and diverse ions. The results for total manganese were in excellent agreement with certified values (Table 3). The reliability of the procedure was tested by recovery studies. The average percentage recovery obtained for addition of manganese(viI) spike to some environmental water samples was quantitative, as shown in Table 4 . The results of biological analyses by the spectrofluorimetric method were in excellent agreement with those obtained by AAS (Table 5). The results of vegetable and fruit samples analyzed by the present method were found to be very much comparable with those found by AAS (Table 8). The results of food analyses by spectrofluorimetric method were also found to be in excellent agreement with those obtained by ICP-MS (Table 9). The results of speciation of manganese(II) and manganese(VII) in mixtures were highly reproducible (Table 10). Statistical comparison of proposed method with reference methods are shown in Table 11. Hence, the precision and accuracy of the method were found to be excellent.

\section{Nature of the fluorescent species}

The non fluorescent reagent, PTQA, produced the same spectral characteristics with excitation and emission wavelengths almost invariably around $319 \mathrm{~nm}$ and $373 \mathrm{~nm}$, with manganese(VII), chromium(VI), selenium(Iv) and cerium(IV) and with persulphate, hydrogen peroxide, and triiodide in acidic media. This indicates that the fluorescence species is an oxidized product of the reagent itself and not a chelate. Similar oxidative fluorescent reactions have been utilized previously. ${ }^{47}$ The PTQA reagent produced here has so many potential reaction sites that the structure of the oxidized fluorescent species is difficult to predict. Given that ring closure can lead to intense fluoresce in some circumstances, it seems likely that photo-oxidative cyclization takes place, leading to the formation of structure (A) in resonance with structure (B) (Fig. 8).<smiles>S=C(Nc1ccccc1)c1ccc2ccccc2n1</smiles><smiles>S=c1[nH]c2ncccc2c2cc3ccccc3nc12</smiles>

(A)

(B)

Fig. 8 Mechanism of oxidative cyclization reaction of 2 -( $\alpha$-pyridyl)thioquinaldinamide (PTQA).

\section{Applications}

The present method was successfully applied to the determination of manganese(vII) in a series of synthetic mixtures of various compositions and also in a number of real samples e.g. several Certified Reference Materials (CRM) (Table 3). The method was also extended to the determination of manganese in a number of environmental, biological, soil, food, tea, fertilizer, vegetable, fruit and pharmaceutical samples. In view of the unknown composition of environmental water samples, the same equivalent portions of each such sample were analyzed for manganese content; the recoveries in both the "spiked" (added to the samples before the mineralization or dissolution) and the "unspiked" samples are in excellent agreement (Table 4). The results of biological analyses by spectrofluorimetric method were found to be in excellent agreement with those obtained by AAS (Table 5). The results of soil analyses by the spectrofluorimetric method are shown in Table 6 . The results of pharmaceutical samples by the spectrofluorimetric method are shown in Table 7. The results of vegetable and fruit 
Table 6 Determination of manganese in some surface soil

\begin{tabular}{lrll}
\hline Serial no. & Manganese $^{a}\left(\mathrm{mg} \mathrm{kg}^{-1}\right)(n=5)$ & RSD (\%) & Sample source $^{b}$ \\
\hline $\mathrm{S}_{1}{ }^{b}$ & $3.5 \pm 0.5$ & 1.8 & Agriculture soil (Chittagong University Campus) \\
$\mathrm{S}_{2}$ & $1.05 \pm 0.3$ & 1.5 & Marine soil (Bay of Bengal) \\
$\mathrm{S}_{3}$ & $21.5 \pm 1.0$ & 1.8 & Traffic soil (Kadamtali Bus Terminal) \\
$\mathrm{S}_{4}$ & $95.6 \pm 1.5$ & 2.2 & Industrial soil (T. S. P. Complex, Chittagong) \\
$\mathrm{S}_{5}$ & $78.5 \pm 1.0$ & 2.3 & Industrial soil (Eastern refinery, Chittagong, Bangladesh) \\
$\mathrm{S}_{6}$ & $130.5 \pm 1.3$ & 2.5 & Industrial soil (Eastern Cables) \\
$\mathrm{S}_{7}$ & $145.0 \pm 1.0$ & 2.0 & Industrial soil (P·H·P glass) \\
$\mathrm{S}_{8}$ & $7.85 \pm 0.8$ & 2.1 & Road side soil (Dhaka-Chittagong Highway) \\
$\mathrm{S}_{9}$ & $117.0 \pm 1.5$ & 2.0 & Paint soil (Berger paint, Chittagong) \\
$\mathrm{S}_{10}$ & $7.5 \pm 0.8$ & 1.8 & River soil (River Karnaphuly, Chittagong)
\end{tabular}

${ }^{a}$ Average of five analyses of each sample. ${ }^{b}$ Composition of the soil samples: C, N, P, K, Na, Ca, Mg, Cu, Mo, Fe, Pb, V, $\mathrm{Zn}, \mathrm{Mn}, \mathrm{Co}, \mathrm{NO}_{3}, \mathrm{SO}{ }_{4}$ etc.

samples by the spectrofluorimetric method were found to be in excellent agreement with that of found by AAS (Table 8). The results of food analyses by spectrofluorimetric method were also found to be in good agreement with those obtained by ICP-MS (Table 9). The results of speciation of manganese(II) and manganese(VII) in mixtures are shown in Table 10. Statistical comparison of proposed method with reference methods are shown in Table 11.

\section{Determination of manganese in synthetic mixtures}

Several synthetic mixtures of varying compositions containing manganese(VII) and diverse ions of known concentrations were determined by the present method using EDTA as masking agent. The results were found to be highly reproducible. Accurate recoveries were achieved in all solutions in the range $98 \pm$ 0.5 to $100 \pm 0.0 \%$. The reliability of our manganese-PTQA

Table 7 Determination of manganese in some pharmaceutical samples

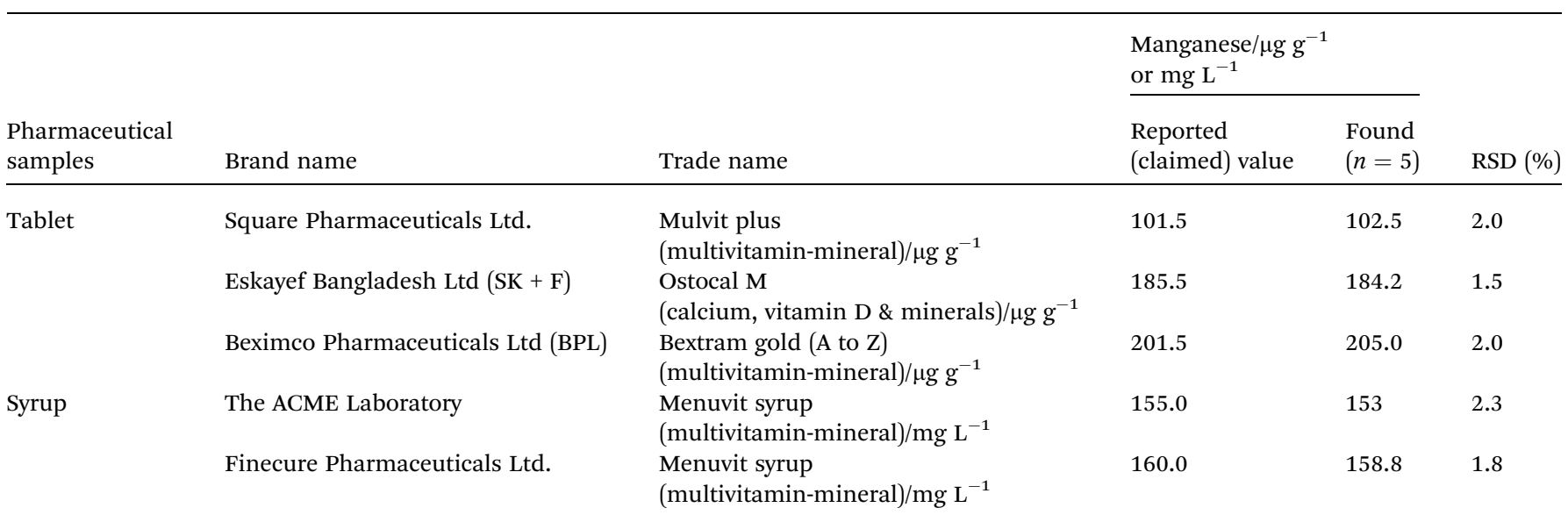

Table 8 Determination of manganese in some vegetable and fruit samples

\begin{tabular}{|c|c|c|c|c|c|c|}
\hline \multirow{2}{*}{ Serial no. } & \multirow{2}{*}{ Sample } & \multicolumn{4}{|c|}{ Manganese $/ \mathrm{mg} \mathrm{kg}^{-1}$ Found $^{a} \pm s(n=5)$} & \multirow{2}{*}{ Sample source } \\
\hline & & \multicolumn{2}{|c|}{$\operatorname{AAS}(n=5)$} & \multicolumn{2}{|c|}{ Proposed method } & \\
\hline 1 & White cabbage (Brassica oleraceacupitata) & 20.5 & 1.0 & 21.8 & 1.2 & Local market, Chittagong \\
\hline 2 & Radish (Raphanus sativus) & 29.5 & 1.5 & 30.0 & 2.0 & Local market, Chittagong \\
\hline 5 & Onion (Allium cepa) & 75.5 & 1.8 & 78.0 & 2.0 & Local market, Chittagong \\
\hline 6 & Coriander seeds (Coriandrum sativum) & 40.5 & 2.0 & 41.5 & 1.8 & Local market, Chittagong \\
\hline 7 & Potato (Solanum tuberosum) & 7.50 & 1.4 & 8.50 & 1.5 & Local market, Chittagong \\
\hline 8 & Garlic (Allium sativum) & 49.5 & 1.5 & 50.4 & 1.9 & Local market, Chittagong \\
\hline
\end{tabular}

${ }^{a}$ Average of five replicate analyses of each sample. ${ }^{b}$ The measure of precision is the relative standard deviation (RSD). 
Table 9 Determination of manganese in some food and tea samples

\begin{tabular}{|c|c|c|c|c|c|}
\hline \multirow{2}{*}{ Sample $^{a}$} & & \multicolumn{4}{|c|}{ Manganese/ $/ \mu \mathrm{g} \mathrm{g}^{-1}$} \\
\hline & & \multicolumn{2}{|c|}{ ICP-MS $(n=5)$} & \multicolumn{2}{|c|}{ Proposed method $(n=5)$} \\
\hline \multirow[t]{3}{*}{ Tea (Camellia sinensis) } & Proyash tea & 285.8 & 1.8 & 289.5 & 1.5 \\
\hline & Ispahani tea & 282.4 & 1.9 & 285.0 & 1.7 \\
\hline & Green tea & 295.5 & 2.0 & 198.2 & 1.8 \\
\hline Rice (Oryza sativa) & & 1.95 & 1.0 & 1.98 & 1.2 \\
\hline Wheat (Triticum aestivum) & & 2.88 & 1.6 & 2.91 & 1.6 \\
\hline
\end{tabular}

procedure was approved by quantitative recovery of manganese(vII) spiked in several synthetic mixtures containing manganese(vII) and diverse ions. The method has high precision and accuracy $\left(s= \pm 0.01\right.$ for $\left.0.5 \mu \mathrm{g} \mathrm{L}{ }^{-1}\right)$.

\section{Determination of manganese in certified reference materials}

A $0.1 \mathrm{~g}$ amount of an alloy or steel sample containing $0.472-$ $1.36 \%$ of manganese was weighed accurately and placed in a $50 \mathrm{~mL}$ Erlenmeyer flask in presence of excess oxidizing agent

Table 10 Determination of manganese(॥) and manganese(VI) in mixtures

\begin{tabular}{|c|c|c|c|c|c|c|c|}
\hline \multirow[b]{2}{*}{ Serial no. } & \multirow{2}{*}{$\begin{array}{l}\text { Mn(VII) : } \\
\operatorname{Mn}(\mathrm{II})\end{array}$} & \multicolumn{2}{|c|}{$\begin{array}{l}\text { Mn, taken } \\
\left(\mu \mathrm{g} \mathrm{L}^{-1}\right)\end{array}$} & \multicolumn{2}{|c|}{$\begin{array}{l}\text { Mn, found } \\
\left(\mu \mathrm{L} \mathrm{L}^{-1}\right)\end{array}$} & \multicolumn{2}{|c|}{ Error $\left(\mu g \mathrm{~L}^{-1}\right)$} \\
\hline & & $\mathrm{Mn}(\mathrm{VII})$ & $\mathrm{Mn}$ (II) & $\mathrm{Mn}(\mathrm{VII})$ & $\mathrm{Mn}$ (II) & $\mathrm{Mn}(\mathrm{VII})$ & $\mathrm{Mn}$ (II) \\
\hline 1 & $1: 1$ & 10 & 10 & 9.98 & 9.99 & 0.02 & 0.01 \\
\hline 1 & $1: 1$ & 10 & 10 & 10.00 & 10.02 & 0.00 & 0.02 \\
\hline 1 & $1: 1$ & 10 & 10 & 9.97 & 9.98 & 0.03 & 0.02 \\
\hline \multicolumn{8}{|c|}{ Mean error: $\mathrm{Mn}(\mathrm{vII})= \pm 0.017 ; \mathrm{Mn}(\mathrm{II})= \pm 0.017$} \\
\hline \multirow[b]{2}{*}{ Serial no. } & \multirow{2}{*}{$\begin{array}{l}\text { Mn(VII): } \\
\text { Mn(II) }\end{array}$} & \multicolumn{2}{|c|}{$\begin{array}{l}\text { Mn, taken } \\
\left(\mu \mathrm{g} \mathrm{L}^{-1}\right)\end{array}$} & \multicolumn{2}{|c|}{$\begin{array}{l}\text { Mn, found } \\
\left(\mu \mathrm{L} \mathrm{L}^{-1}\right)\end{array}$} & \multicolumn{2}{|c|}{ Error $\left(\mu \mathrm{g} \mathrm{L}^{-1}\right)$} \\
\hline & & $\operatorname{Mn}(\mathrm{VII})$ & $\operatorname{Mn}($ II) & $\mathrm{Mn}(\mathrm{VII})$ & $\mathrm{Mn}(\mathrm{II})$ & $\mathrm{Mn}(\mathrm{VII})$ & $\operatorname{Mn}(\mathrm{II})$ \\
\hline 1 & $1: 5$ & 10 & 50 & 9.98 & 49.80 & 0.02 & 0.20 \\
\hline 1 & $1: 5$ & 10 & 50 & 9.99 & 49.70 & 0.01 & 0.30 \\
\hline 1 & $1: 5$ & 10 & 50 & 9.98 & 49.80 & 0.02 & 0.20 \\
\hline
\end{tabular}

\begin{tabular}{|c|c|c|c|c|c|c|c|}
\hline \multirow[b]{2}{*}{ Serial no. } & \multirow{2}{*}{$\begin{array}{l}\mathrm{Mn}(\mathrm{VII}): \\
\mathrm{Mn} \text { (II) }\end{array}$} & \multicolumn{2}{|c|}{$\begin{array}{l}\text { Mn, taken } \\
\left(\mu \mathrm{g} \mathrm{L}^{-1}\right)\end{array}$} & \multicolumn{2}{|c|}{$\begin{array}{l}\text { Mn, found } \\
\left(\mu \mathrm{g} \mathrm{L}^{-1}\right)\end{array}$} & \multicolumn{2}{|c|}{ Error $\left(\mu \mathrm{g} \mathrm{L}^{-1}\right)$} \\
\hline & & $\operatorname{Mn}(\mathrm{VII})$ & $\operatorname{Mn}(\mathrm{II})$ & $\mathrm{Mn}(\mathrm{VII})$ & $\operatorname{Mn}(\mathrm{II})$ & $\mathrm{Mn}(\mathrm{VII})$ & $\mathrm{Mn}(\mathrm{II})$ \\
\hline 1 & $1: 10$ & 10 & 100 & 9.99 & 99.8 & 0.01 & 0.2 \\
\hline 1 & $1: 10$ & 10 & 100 & 9.98 & 99.9 & 0.02 & 0.1 \\
\hline 1 & $1: 10$ & 10 & 100 & 9.97 & 99.8 & 0.03 & 0.2 \\
\hline
\end{tabular}

Mean error: $\mathrm{Mn}(\mathrm{VII})= \pm 0.02 ; \mathrm{Mn}(\mathrm{II})= \pm 0.17$

Standard deviation: $\mathrm{Mn}(\mathrm{VII})= \pm 0.0019 ; \mathrm{Mn}(\mathrm{II})= \pm 0.0018$ following a method recommended by Parker. ${ }^{48}$ To it, $10 \mathrm{~mL}$ of $20 \%(\mathrm{w} / \mathrm{v})$ sulfuric acid was added and the mixture was heated gently. The residual carbides were decomposed by gently simmering with $1 \mathrm{~mL}$ of concentrated $\mathrm{H}_{3} \mathrm{PO}_{4}$ and $10 \mathrm{~mL}$ of concentrated $\mathrm{HNO}_{3}$. Then a further $2 \mathrm{~mL}$ of $1+1 \mathrm{H}_{2} \mathrm{SO}_{4}$ and $2 \mathrm{~mL} 2 \% \mathrm{w} / \mathrm{v}$ freshly prepared persulphate were added and the solution was evaporated carefully to dense white fumes of sulphur trioxide, then cooled to room temperature $\left(25 \pm 5{ }^{\circ} \mathrm{C}\right)$.

Table 11 Statistical comparison of proposed method with reference methods

\begin{tabular}{|c|c|c|c|c|c|}
\hline \multirow[b]{2}{*}{ Samples } & \multicolumn{5}{|c|}{$\mathrm{F}-$ test results $^{a}$} \\
\hline & $\left(s_{1}{ }^{2} / s_{2}{ }^{2}\right)^{15}$ & $\left(s_{1}{ }^{2} / s_{3}{ }^{2}\right)^{26}$ & $\left(s_{1}{ }^{2} / s_{4}{ }^{2}\right)^{31}$ & $\left(s_{1}{ }^{2} / s_{5}{ }^{2}\right)^{33}$ & $\left(s_{1}{ }^{2} / s_{6}{ }^{2}\right)^{28}$ \\
\hline Water & 0.127 & & 0.58 & 0.23 & 0.0019 \\
\hline Water & 0.0516 & & 0.063 & 0.028 & 0.37 \\
\hline Water & 0.219 & & 0.100 & 0.273 & \\
\hline Water & 0.119 & & & & \\
\hline Blood & 0.95 & & & & \\
\hline Blood & 0.52 & & & & \\
\hline Blood & 0.73 & & & & \\
\hline Soil & & 0.32 & 0.0002 & 0.0004 & \\
\hline Soil & & 0.95 & 0.0003 & 0.0007 & \\
\hline Soil & & 1.0 & 0.0001 & 0.0001 & \\
\hline Alloy & & 0.074 & & & \\
\hline Alloy & & 0.12 & & & \\
\hline $\begin{array}{l}\text { Synthetic } \\
\text { mixture }\end{array}$ & & 0.13 & & & \\
\hline $\begin{array}{l}\text { Synthetic } \\
\text { mixture }\end{array}$ & & 0.52 & & & \\
\hline $\begin{array}{l}\text { Synthetic } \\
\text { mixture }\end{array}$ & & 0.72 & & & \\
\hline Food & & & 0.79 & & \\
\hline Food & & & 0.68 & & \\
\hline Urine & & & & 1.02 & \\
\hline Urine & & & & 0.84 & \\
\hline Tea & & & & & 0.98 \\
\hline Wheat & & & & & 0.76 \\
\hline
\end{tabular}

${ }^{a}$ Tabulated F-value for $(5,5)$ degrees of freedom at $P(0.98)$ is 5.72. $s_{1}=$ standard deviation of proposed method, $s_{2}=$ standard deviation of reference method, ${ }^{15} s_{3}=$ standard deviation of reference method, ${ }^{26} s_{4}$ $=$ standard deviation of reference method, ${ }^{31} s_{5}=$ standard deviation of reference method, ${ }^{33} s_{6}=$ standard deviation of reference method. ${ }^{28}$ 
After suitable dilution with de-ionized water, the contents of the Erlenmeyer flask were warmed so as to dilute the soluble salts. The solution was then cooled and neutralized with dilute $\mathrm{NH}_{4} \mathrm{OH}$ in presence of $1-2 \mathrm{~mL}$ of $0.01 \%(\mathrm{w} / \mathrm{v})$ EDTA solution. The resulting solution was filtered if necessary, through a Whatman no. 40 filter paper into a $100 \mathrm{~mL}$ calibrated flask. The residue (silica tungstanic acid) was washed with a small volume of hot $1+99 \mathrm{H}_{2} \mathrm{SO}_{4}$, followed by water; the volume was made up to mark with de-ionized water.

A suitable aliquot (1-2 mL) of the above-mentioned solution was taken into a $10 \mathrm{~mL}$ calibrated flask and the manganese(viI) content was determined; as described under procedure using tartrate or EDTA as masking agent. The proposed procedure for the spectrofluorimetric determination of manganese was applied to the analysis of estuarine sediment (NIST-SRM-1646) and human hair (CRM-BCR-397) CRMs obtained from the National Resource Council of Canada using tartrate or EDTA as a masking agent, following a method recommended by Sun et $a .^{49}$ Based on five replicate analyses, average manganese concentration determined by spectrofluorimetric method was in excellent agreement with the certified values. The results are given in Table 3.

\section{Determination of manganese in environmental water samples}

Each filtered (with Whatman no. 40) environmental sample $(25 \mathrm{~mL}$ ) contained in a $50 \mathrm{~mL}$ Pyrex beaker were added $1 \mathrm{~mL}$ of concentrated $\mathrm{H}_{2} \mathrm{SO}_{4}, 1 \mathrm{~mL}$ of concentrated $\mathrm{H}_{3} \mathrm{PO}_{4}$ and $2 \mathrm{~mL}$ of concentrated $\mathrm{HNO}_{3}$ and the mixture was heated on a hot plate until white fumes of sulphur trioxide; in the presence of freshly prepared $2 \mathrm{~mL}$ of $2 \%(\mathrm{w} / \mathrm{v})$ persulphate solution in a fume cupboard to oxidize manganese(II) to manganese(viI) following a method recommended by Greenberg et al. ${ }^{50}$

An aliquot (1-2 mL) of this water sample was pipetted into a $10 \mathrm{~mL}$ calibrated flask and the manganese content was determined as described under the general procedure using tartrate or EDTA as masking agent. The results of analyses of environmental water samples from various sources for manganese are shown in Table 4.

Spectrofluorimetric methods for determination of manganese in natural and sea-water does not require any preconcentration of manganese. ${ }^{51}$ The concentration of manganese in natural and sea water is a few $\mu \mathrm{g} \mathrm{L}^{-1}$ in developed countries. ${ }^{52}$ The mean concentration of manganese found in U.S. drinking water is greater than $20 \mu \mathrm{g} \mathrm{L}^{-1} .^{52}$

\section{Determination of manganese in biological samples}

Human blood (1-2 mL) or urine (5-10 mL) or hair (1-2 g) sample was taken into a $100 \mathrm{~mL}$ micro-Kjeldahl flask. A glass bead and $10 \mathrm{~mL}$ of concentrated nitric acid were added, and the flask was placed on the digester under gentle heating. The sample was digested in the presence of an excess persulphate solution according to the method recommended by Stahr. ${ }^{53}$ As the heating process continued $1 \mathrm{~mL}$ of $\mathrm{H}_{2} \mathrm{SO}_{4}$ is added and heated for about 0.5 hour to dense white fumes of sulphur trioxide.
When the initial brisk reaction was completed, the solution was removed and cooled at room temperature. A $1 \mathrm{~mL}$ volume of $3.33 \mathrm{M} \mathrm{H}_{3} \mathrm{PO}_{4}$ was carefully added, followed by the addition of $2 \mathrm{~mL}$ of $2 \%(\mathrm{w} / \mathrm{v})$ freshly prepared ammonium persulphate solution to oxidize $\mathrm{Mn}$ (II) to $\mathrm{Mn}$ (VII) and heating was continued to dense white fumes, while repeating the nitric acid addition, if necessary. The solution was then cooled and neutralized with a dilute $\mathrm{NH}_{4} \mathrm{OH}$. The final solution is made up to the mark with de ionized water.

A suitable aliquot (1-2 mL) of the final solution was pipetted out into a $10 \mathrm{~mL}$ calibrated flask and the manganese content was determined as described under procedure using EDTA or tartrate as masking agent. The results of biological analyses by the spectrofluorimetric method were found to be in excellent agreement with those obtained by AAS. The results are shown in Table 5 .

The abnormally high value for the manganism patient is probably due to the involvement of high manganese concentrations with As and $\mathrm{Zn}$. The occurrence of such high manganese contents are also reported in manganism patient from some developed countries. ${ }^{54}$

\section{Determination of manganese in soil samples}

An air-dried homogenized soil sample (10 g) was accurately weighed and placed in a $100 \mathrm{~mL}$ micro-Kjeldahl flask. The sample was digested in the presence of an oxidizing agent $(2 \mathrm{~mL}$ of $2 \%$ freshly prepared ammonium persulphate solution) following method recommended by Jackson. ${ }^{55}$ The solution was cooled and in the resulting solution $1 \mathrm{~mL}$ of $3.33 \mathrm{M} \mathrm{H}_{3} \mathrm{PO}_{4}, 2 \mathrm{~mL}$ of $2 \%(\mathrm{w} / \mathrm{v})$ freshly prepared ammonium persulphate was added. The solution was heated for 5-10 min to affect complete oxidation from manganese(II) to manganese(vII). The solution is reduced in volume by evaporation to eliminate excess persulphate.

The content of the flask was filtered through a Whatman no. 40 filter paper into $25 \mathrm{~mL}$ calibrated flask and neutralized with dilute $\mathrm{NH}_{4} \mathrm{OH}$ solution in the presence of $1-2 \mathrm{~mL}$ of $0.01 \%(\mathrm{w} / \mathrm{v})$ EDTA solution. The resulting solution was then diluted up to the mark with de-ionized water.

A suitable aliquot $(1 \mathrm{~mL})$ of the final solution was pipetted out into a $10 \mathrm{~mL}$ calibrated flask and the manganese content was determined as described under procedure using tartrate or EDTA as masking agent. The manganese content was then determined by the above procedure and quantified from a calibration graph prepared concurrently. The results are shown in Table 6. The average value of manganese in Bangladesh surface soil was found to be $43.29 \mathrm{mg} \mathrm{kg}^{-1} .^{56}$

\section{Determination of manganese in pharmaceutical samples}

Finished pharmaceutical samples (each Mn containing $1 \mathrm{mg}$ tablet or $5 \mathrm{~mL}$ syrup or required weight) were quantitatively taken in a $50 \mathrm{~mL}$ beaker and digested in the presence of excess oxidizing agent following a method recommended by Ahmed et al. ${ }^{57} 10 \mathrm{~mL}$ of concentrated nitric acid is added and heated to dryness and then added $10 \mathrm{~mL}$ of $20 \%(\mathrm{v} / \mathrm{v})$ of $\mathrm{H}_{2} \mathrm{SO}_{4}$ and heated to white fume. In the resulting solution $1 \mathrm{~mL}$ of $3.33 \mathrm{M} \mathrm{H}_{3} \mathrm{PO}_{4}$, 
$2 \mathrm{~mL}$ of $2 \%(\mathrm{w} / \mathrm{v})$ freshly prepared ammonium persulphate is added. The solution is heated for 5-10 min to effect complete oxidation of manganese(II) to manganese(VII). The solution is reduced in volume by evaporation to eliminate excess persulphate. The solution was then cooled and neutralized with dilute $\mathrm{NH}_{4} \mathrm{OH}$ in the presence of $1-2 \mathrm{~mL}$ of $0.01 \%$ (w/v) EDTA solution. The resulting solution was then filtered and quantitatively transferred into a $25 \mathrm{~mL}$ calibrated flask and made up to the mark with de-ionized water.

An aliquot (1-2 mL) of this digested sample was pipetted into a $10 \mathrm{~mL}$ calibrated flask and then manganese content was determined as described under the general procedure using tartrate or EDTA as a masking agent. The results of some pharmaceutical analyses are in excellent agreement with the reported values. The analyses of pharmaceutical samples from several Pharmaceutical Companies for manganese are given in Table 7 .

\section{Determination of manganese in vegetable and fruit samples}

The vegetable and fruit samples collected prior to the determination were pretreated in the following way: edible portion of samples was first washed clean with tap water followed by rewashing with de-ionized water. After removing de-ionized water from the surface of vegetables and fruits, the samples were cut into small pieces and dried at $65{ }^{\circ} \mathrm{C}$ in oven. An air dried vegetables and fruits samples (10 gm) were taken in a $100 \mathrm{~mL}$ micro-Kjeldahl flask in presence of oxidizing agent and digested following a method recommended by Stahr ${ }^{53}$ and $10 \mathrm{~mL}$ of concentrated nitric acid were added and the flask was placed on the digester under gentle heating. When the initial brisk reaction was over, the solution was removed and cooled at room temperature. $1 \mathrm{~mL}$ volume of concentrated sulfuric acid was added carefully, followed by the addition of $2 \mathrm{~mL}$ of concentrated $\mathrm{HF}$, and heating was continued for at least $1 / 2 \mathrm{~h}$ and then cooled. In the resulting solution $1 \mathrm{~mL}$ of $3.33 \mathrm{M}$ $\mathrm{H}_{3} \mathrm{PO}_{4}, 2 \mathrm{~mL}$ of $2 \%(\mathrm{w} / \mathrm{v})$ freshly prepared ammonium persulphate is added. The mixture of each foodstuff was heated below the boiling point for $5-10 \mathrm{~min}$ to oxidize manganese(II) to manganese(VII). The resulting solution was then cooled and neutralized with dilute $\mathrm{NH}_{4} \mathrm{OH}$ in presence of 1-2 $\mathrm{mL}$ of $(\mathrm{w} / \mathrm{v})$ EDTA solution. The resulting solution was filtered and quantitatively transferred into a $25 \mathrm{~mL}$ calibrated flask and mixed well and made up to the mark with de ionized water.

A suitable aliquot (1-2 mL) of the final solution was pipetted into a $10 \mathrm{~mL}$ calibrated flask and the manganese content was determined as described under the procedure using tartrate as masking agent. High value of manganese for Allium cepa (onion) is probably due to the involvement of high manganese concentration in the soil. ${ }^{58}$ The results of vegetable and fruit analysis by spectrofluorimetric method were also found to be in excellent agreement with those obtained by AAS. The results are shown in Table 8.

\section{Determination of manganese in food and tea samples}

The food samples used were rice, wheat and tea and these were used under dry conditions. Each sample was first ground in a mortar. Tea samples $(0.1 \mathrm{~g})$ or rice and wheat samples $(1.0 \mathrm{~g})$ were weighed accurately and placed in a porcelain crucible and charred in an electric furnace; the sample was ashed at $555^{\circ} \mathrm{C}$ in a muffle furnace in presence of excess oxidizing agent following a method recommended by Stahr..$^{53} 2 \mathrm{~mL}$ of $\mathrm{HCl}$ and $10 \mathrm{~mL}$ of water were added to the ash. The mixture of each foodstuff was heated below the boiling point for a moment. In the resulting solution $1 \mathrm{~mL}$ of $3.33 \mathrm{M} \mathrm{H}_{3} \mathrm{PO}_{4}, 2 \mathrm{~mL}$ of $2 \%(\mathrm{w} / \mathrm{v})$ freshly prepared ammonium persulphate is added. The solution is heated for 5-10 min to effect complete oxidation from $\mathrm{Mn}$ (II) to $\mathrm{Mn}(\mathrm{VII})$. The solution was then cooled and neutralized with dilute $\mathrm{NH}_{4} \mathrm{OH}$ in presence of $1-2 \mathrm{~mL}$ of $0.01 \%(\mathrm{w} / \mathrm{v})$ EDTA solution and filtered. The resulting solution was quantitatively transferred transferred into a $25 \mathrm{~mL}$ calibrated flask and mixed well and made up to the mark with de-ionized water.

A suitable aliquot (1-2 mL) of the final solution was pipetted out into a $10 \mathrm{~mL}$ calibrated flask and the manganese content was determined as described under procedure using tartrate as masking agent. The results of food analyses by the spectrofluorimetric method were also found to be in excellent agreement with those obtained by ICP-MS. The results are shown in Table 9.

High value of manganese for Camellia sinensis (green tea) is probably due to the involvement of high manganese concentration in the soil.

\section{Determination of manganese(II) and manganese(VII) speciation in mixtures}

Suitable aliquots (1-2 mL) of manganese (VII + II) mixtures (preferably $1: 1,1: 5,1: 10$ ) were taken in a $25 \mathrm{~mL}$ Pyrex beaker. In this solution $1 \mathrm{~mL}$ of $3.33 \mathrm{M} \mathrm{H}_{3} \mathrm{PO}_{4}, 1 \mathrm{~mL}$ of $10^{-4} \mathrm{M}$ silver nitrate and $2 \mathrm{~mL}$ of $2 \%(\mathrm{w} / \mathrm{v})$ freshly prepared ammonium persulphate is added. The solution (4-5 mL) is heated for 5$10 \mathrm{~min}$ to effect complete oxidation to convert all $\mathrm{Mn}$ (II) into $\mathrm{Mn}(\mathrm{VII})$. The solution is reduced in volume by evaporation to half of its initial volume to eliminate excess persulphate. The solution was then cooled and neutralized with dilute $\mathrm{NH}_{4} \mathrm{OH}$. The solution is taken quantitatively in to $10 \mathrm{~mL}$ volumetric flux and $1 \mathrm{~mL}$ of $1 \times 10^{-4} \mathrm{M}$ PTQA reagent solution was added followed by the addition of $1 \mathrm{~mL}$ of $0.025 \mathrm{M} \mathrm{H}_{2} \mathrm{SO}_{4}$ and $2 \mathrm{~mL}$ ethanol. It was made up to the mark with de-ionized water. The fluorescence intensity was measured after $5 \mathrm{~min}$ at $373 \mathrm{~nm}$ when excited at $319 \mathrm{~nm}$, against a reagent blank. The total manganese content was calculated with the help of a calibration graph prepared concurrently. ${ }^{58,59}$

An equal aliquot (1-2 mL) of the above manganese (VII + II) mixture was taken into a $25 \mathrm{~mL}$ beaker. Neutralize the solution with dilute $\mathrm{NH}_{4} \mathrm{OH}$ in presence of $1-2 \mathrm{~mL}$ of $0.01 \%(\mathrm{w} / \mathrm{v})$ tartrate solution. After, the content of the beaker was transferred quantitatively into a $10 \mathrm{~mL}$ volumetric flask, $1 \mathrm{~mL}$ of $1 \times 10^{-4} \mathrm{M}$ PTQA reagent solution was added, followed by the addition of $1 \mathrm{~mL}$ of $0.025 \mathrm{M} \mathrm{H}_{2} \mathrm{SO}_{4}$ and $2 \mathrm{~mL}$ ethanol. It was made up to the mark with de-ionized water. After $5 \mathrm{~min}$ the fluorescence intensity was measured at $373 \mathrm{~nm}$ when excited at $319 \mathrm{~nm}$ against a reagent blank, as before. The manganese concentration was calculated in $\mu \mathrm{g} \mathrm{L}^{-1}$ or $\mathrm{ng} \mathrm{L}^{-1}$ with the aid of 
a calibration graph. This gives a measure of manganese(viI) originally present in the mixture. This value was subtracted from that of the total manganese to get the manganese(II) present in the mixture. The results were found to be highly reproducible. The occurrence of such reproducible results is also reported for different oxidation states of manganese. ${ }^{60}$ The results of a set of determination are given in Table 10 .

The present method was compared with some reported methods ${ }^{15,26,28,31,33}$ statistically. It was found that present method is much superior those of the reported methods. The results are shown in Table 11.

\section{Conclusions}

A new simple, ultra sensitive, highly selective and inexpensive spectrofluorimetric method with the manganese(vII)-PTQA system was developed for the determination of manganese in some real, environmental, biological, soil, food, vegetable, fruit and pharmaceutical samples, for continuous monitoring to establish the nano-trace levels of manganese in different samples matrices. Compared with other methods ${ }^{\mathbf{4 - 4 0}}$ in the literature, the proposed method has several remarkable analytical characteristics. Firstly, the proposed method is highly sensitive that amount of $\mathrm{ng} \mathrm{\textrm {L } ^ { - 1 }}$ of manganese can be determined without preconcentration. Secondly, the proposed method is very simple, rapid, and stable. The reaction of manganese(VII) with PTQA is completed rapidly in $1 \mathrm{~min}$ at room temperature so it does not involve any stringent reaction conditions and offer the advantages of stability of fluorescence intensity ( $24 \mathrm{~h}$ ). Thirdly, the method has added the advantage of determining individual amounts of $\mathrm{Mn}$ (VII) and Mn(II). With suitable masking agents, the reaction can be made highly selective. The proposed method using PTQA in aqueous solutions not only is one of the most sensitive methods for the determination of manganese but also is excellent in terms of selectivity and simplicity. Therefore, this method will be successfully applied to the monitoring of nano-trace amounts of manganese in real, environmental, biological, soil, fruit, vegetables, food and pharmaceutical samples.

\section{Conflicts of interest}

There are no conflicts to declare.

\section{Acknowledgements}

The authors are grateful to the authorities of Chittagong Medical College Hospital for their generous help in supplying biological samples. We are especially indebted to the authorities of BCSIR Laboratories, Chittagong for analyzing the biological and food samples by AAS and ICP-MS, respectively. We are also thankful to the Director of the Center of Excellence in Analytical Chemistry, University of Sindh, Jamshro, Pakistan for elemental analysis of our prepared reagent. We are also thankful to the department of Chemistry, University of Kanazawa, Japan for ${ }^{1} \mathrm{NMR}$ analysis of our prepared reagent.

\section{References}

1 www.en.wikipedia/org/wiki/manganese.com.

2 www.lenntech.com/periodic/elements/mn.htm.

3 www.chemistry.about.com/od/elementfacts/a/manganese.htm.

4 G. G. Guilbault, Anal. Chem., 1968, 40, 459-471.

5 A. Navas and F. S. Rojas, Talanta, 1984, 31, 437-449.

6 B. K. Pal, M. Jamaluddin Ahmed and A. K. Chakrabarti, Analyst, 1990, 115, 439-443.

7 W. Ruiz, Talanta, 1984, 31, 29-32.

8 S. Rubio, G. H. Agustina and M. Valcárcel, Analyst, 1984, 109, 715-717.

9 F. J. L. Benet, F. Hernández, J. M. Escriche and R. M. Saez, Analyst, 1986, 111, 1325-1331.

10 D. P. Bendito, J. Peinado and F. Toribio, Analyst, 1984, 109, 1497-1502.

11 Z. T. Jiang and R. Li, Chem. Anal., 2008, 53, 647-659.

12 F. Lazaro, M. D. Luque De Castrto and M. Valcarcel, Anal. Chim. Acta, 1985, 169, 141-147.

13 M. Y. Fujita, K. Ikuta, Y. Nakahashi and K. Kato, Fresenius $Z$. Anal. Chem., 1989, 334(3), 252-259.

14 S. Huiming, T. Bo and Y. Yiqiong, Chin. J. Anal. Chem., 1992, 20, 1043-1048.

15 Y. Yu, C. Hong, R. Wang and J. Huang, Chin. J. Anal. Chem., 1998, 26, 410-414.

16 Z. G. Cheng, Phys. Test. Chem. Anal. Part A Phys. Test., 2004, 12, 1-45.

17 V. L. Biddle and E. L. Wehry, Am. J. Anal. Chem., 1978, 50, 865-867.

18 J. Juhui, Z. Luqing, C. Dingxi and Z. Gui'en, Anal. Lab., 1999, 01, 47-53.

19 Z. Shuxian, A. Gaowa, S. Gaowa, S. Yin and Y. Wenbin, Chin. J. Anal. Chem., 1995, 23, 393-398.

20 G. C Ragos, M. A. Demertzis and P. B. Issopoulos, Farmaco, 1997, 52, 199-203.

21 W. Kunihiro, R. Kazuhiro and I. Masayuki, Bunseki Kagaku, 2009, 44, 929-933.

22 F. Yang, G. J. X. Zhao, L. J. Qia, L. I. M. Jing and C. U. I. X. Yu, Chin. J. Spectrosc. Lab., 2013, 30, 2365-2371.

23 C. S. jie, L. I. Ying-jiea and Q. Cheng-lib, Chem. Reagents, 2010, 3, 87 .

24 B. Tang and F. Han, Anal. Lett., 2001, 34, 1353-1368.

25 Z. Zhiqi, X. Fenghe and G. Xiaodan, Chin. J. Anal. Chem., 1989, 17, 749-753.

26 A. Moreno, M. Silva and D. Perez-Bendito, Anal. Chim. Acta, 1984, 159, 319-328.

27 T. Xiu-lan, M. A. Yong-jun, Z. Min, P. Yu-ying and Y. Haiqing, Chem. Reagents, 2009, 8, 16-31.

28 G. S. guang, Z. Li-na, D. Ping, C. Xiao-liang and Y. Jing-hua, Chin. J. Anal. Lab., 2008, 11, 39-44.

29 H. Shuhui, H. Youying and C. Lanhua, J. Huaibei Ind. Teach. Coll., Nat. Sci. Ed., 1993, 03, 3-10.

30 Z. Zhaosheng and L. Tong, Chin. J. Anal. Chem., 1990, 18, 1071-1079.

31 Q. Shan-bao and Y. Hai-yan, Stud. Trace Elem. Health, 2004, 1, 11-30. 
32 Z. Lina, G. Shenguang, Z. Yan and L. Haiyun, Phys. Test. Chem. Anal., 2008, 9, 1-20.

33 Z. Guien, C. Dingxi and F. Suling, Chin. J. Anal. Chem., 1993, 8, 148-153.

34 P. Zhigong, W. Baoqi and W. Congying, Anal. Lab., 1994, 01, 11-15.

35 L. Verne, E. Biddle and L. Wehry, Anal. Chem., 1978, 50, 867870.

36 A. Moreno, M. Silva and D. Perez-Bendito, Anal. Chim. Acta, 1984, 159, 319-328.

37 A. D. Sherry and G. L. Cottam, Arch. Biochem. Biophys., 1973, 156, 665-672.

38 A. D. Gaowa, S. Yin, Y. Jinlong and Z. A. Shuxian, Anal. Lab., 1995, 3, 23-30.

39 X. Yu-sheng and Q. Shan-bao, J. South. Yangtze Univ., Nat. Sci. Ed., 2004, 6, 187-196.

40 Y. Ying, H. Jianfeng and D. Feng, Chin. J. Anal. Chem., 1997, 5, 17-26.

41 H. D. Porter, J. Am. Chem. Soc., 1954, 76, 127-131.

42 G. H. Jeffery, J. Bassett, J. Mendham and R. C. Denney, Textbook of Quantitative Inorganic Analysis, John Wiley and Sons Inc, 5th edn, New York, 1989, pp. 309-368.

43 A. K. Mukharjee, Analytical Chemistry of Zirconium and Hafnium, Pergamon Press, 1st edn, New York, 1970, pp. 12-37.

44 B. K. Pal and B. Chowdhury, Mikrochim. Acta, 1984, 11, 121127.

45 B. K. Pal and D. E. Ryan, Anal. Chim. Acta, 1969, 47, 227-231.

46 A. Pierre, D. Karine, D. Franck and C. Gwenaelle, Chem. Geol., 2005, 218, 265-279.

47 B. K. Pal, F. Toneguzzo, A. Corsini and D. E. Ryan, Anal. Chim. Acta, 1977, 88, 353-361.
48 G. A. Parker, Analytical Chemistry of Molybdenum, SpringerVerlag, Berlin, 1983.

49 C. Sun, J. Y. Yang and S. R. Tzeng, Analyst, 1999, 124, 421429.

50 Standard Methods for the Examination of Water and Wastewater, ed. E. A. Greenberg, S. L. Clesceri and D. A. Eaton, American Public Health Association, 18th edn, Washington D. C., 1992, p. 53.

51 C. Ojeda, A. Garcia de Torres, F. Sanchez Rojas and J. M. Cano Pavon, Analyst, 1987, 112, 1499-1502.

52 Manganese in Drinking Water, World Health Organization, 1992, pp. 1-15.

53 H. M. Stahr, Analytical Methods in Toxicology, John Wiley and Sons, 3rd edn, New York, 1991, pp. 75-85.

54 American Conference of Governmental Industrial Hygienists (ACGIH), Threshold limit values for chemical substances and physical agents and biological exposure indices for 1995/96, ACGIH, Cincinnati, OH, 1996.

55 M. L. Jackson, Soil Chemical Analysis, Prentice Hall, Englewood Cliffs, 1965, pp. 326-337.

56 A. L. Page, A. C. Chang and M. El-Amany, in: Lead, Mercury, Cadmium, Manganese and Arsenic in the Environment, ed. T. C. Hutchinsm and K. M. Mecma, John Wiley and Sons Ltd., New York, 1987, p. 119.

57 M. Jamaluddin Ahmed, M. Reazul Houqe, A. S. M. Shahed Hossain Khan and S. C. Bhattacharjee, Eurasian J. Anal. Chem., 2010, 5, 1-15.

58 H. P. Beck, D. Kostova and B. Zhang, Agron. Res., 2006, 4(2), 493-498.

59 L. F. Delgadillo, G. H. Silva, R. A. Martinez and M. M. Vermeerch, Rev. Int. Contam. Ambient., 1992, 8, 37-46.

60 A. Pierre, D. Karine, D. Franck and C. Gwenalle, Chem. Geol., 2005, 218, 265-279. 